\title{
Representações midiáticas de corpo, gênero e sexualidade - uma análise da série Orange Is The New Black
}

Tainá Cordova Schlösser tainaschlosser@gmail.com orcid.org/0000-0001-6010-1039 Universidade Federal do Paraná (UFPR), Curitiba, Paraná, Brasil

Patricia Barbosa Pereira patriciapereira@ufpr.br orcid.org/0000-0002-2984-2872 Universidade Federal do Paraná (UFPR), Curitiba, Paraná, Brasil

\section{RESUMO}

As mídias atravessam, definem e perfazem nossas interações cotidianas. Na escola isto não tem sido diferente. No entanto, por falta de apropriação teórico-prática e pouca visibilidade didática, alguns artefatos midiáticos, quando associados ao aspecto pedagógico, podem ser generalizados negativamente como vilões e causadores da indisciplina. Partindo dessas ideias, bem como de nossas vivências no âmbito escolar, juntamente com a assunção de alguns assuntos polêmicos/tabus em discursos que circulam na atualidade, o presente artigo trará a análise de trechos da série estadunidense "Orange Is The New Black", acessada com frequência por jovens e adolescentes em idade escolar. Para tal, faremos uso da Análise de Discurso francesa (AD), com a intenção de discutir como os temas sexualidade, corpo e gênero são representados na série, além de analisarmos como essas representações podem influenciar na construção de sentidos acerca de tais temas. Buscaremos verificar, também, se existe a possibilidade de se aprender com as mídias no escopo do Ensino de Ciências, em uma abordagem mais contextualizada quanto à educação sexual. A série apresenta conteúdos sociais, os quais podem ser discutidos em sala de aula para o estudo de temas transversais, principalmente em relação à educação sexual e no que diz respeito aos temas sexualidade, corpo e gênero, em uma alternativa à abordagem biológicahigienista, a partir de outros aspectos como os direitos humanos e sexuais.

PALAVRAS-CHAVE: Mídias. Sexualidade, Corpo e Gênero. Educação Sexual. Análise de Discurso. 


\section{INTRODUÇÃO}

O avanço das tecnologias se reflete no comportamento de toda a sociedade. Um dos desdobramentos dessa mudança está no crescente número de crianças e adolescentes, a chamada "Geração Net" ou "Geração Y", que ao invés de saírem para brincar, praticar esportes ou até mesmo socializar com outras pessoas de mesma idade, preferem fazê-los por intermédio de tecnologias. Reeves (2008) caracteriza a "Geração Net", que não possui faixa etária definida, por sempre estar conectada a computadores, celulares e tablets - jogando online, vendo séries, desenhos, filmes e se relacionando virtualmente, tanto com pessoas conhecidas, quanto desconhecidas. Estudos trazem as consequências de se ficar online 24 horas por dia. Dentre elas estão: a diminuição do contato social físico, pois este é substituído pelas redes sociais; o grande aumento de doenças psicológicas através do cyberbullying; além de doenças físicas, que também estão na lista, como problemas de coluna, de visão e o sobrepeso (GAMBARDELLA; BISMARCK-NASI, 2000). Assim, percebe-se uma preocupação de se tratar tais problemas e entender como eles poderão afetar essa geração quando adulta.

Outro avanço se relaciona aos conteúdos presentes nas mídias, que são consequentes dessa expansão e aprimoramento tecnológico - e aqui cabem todas elas, desde as sociais até as televisivas. Nesses espaços, assuntos ditos tabus são transmitidos e discutidos. Porém, em tal contexto, alguns pontos importantes a serem levantados são: que tipo de conteúdo tais mídias abordam? E, em relação à veracidade de tais conteúdos, qual é a atenção dada pelos produtores de novelas e filmes, por exemplo, ao destinarem o foco a tais assuntos? Como, afinal, esses conteúdos podem influenciar a vida de jovens e adolescentes? Como eles podem interpretar o que é veiculado, diariamente, pelas mídias?

O presente artigo visa discutir, por meio da Análise de Discurso da linha francesa ( $A D)$, como os conteúdos midiáticos representam os temas: sexualidade, corpo e gênero, e como sua abordagem interfere/influencia na construção de sentidos que apontem para esses temas. Tais temáticas são tratadas de diversas formas, por diversos meios de comunicação, como revistas, jornais, novelas, filmes e séries. Embora não só adolescentes e jovens sejam influenciados por esses discursos, se ater às formas como esse público está aprendendo parece ser um ponto importante, no sentido de assegurar a qualidade de formação, diante de tantas fragilidades, intolerâncias e retrocessos que se disseminam em nossa sociedade. Em consonância com Ramos (2006), percebemos, também, a importância de tratar os dois assuntos de forma conjunta, atrelados à educação, pois as mídias também propiciam formas de aprendizado significativo.

Perceber a crescente procura por séries, principalmente por jovens e adolescentes, traz a necessidade de um olhar mais atento para as possibilidades de apropriação cultural promovidas pelas mídias. Tal necessidade está vinculada a constituição de identidades culturais locais daqueles que estão em formação e, além do que, estarão exercendo sua liberdade de expressão, difundindo, através de redes sociais, em ambientes formais ou informais, os conceitos e ideias "absorvidos". Por isso, em consonância com Bévort e Belloni (2009) destacamos a importância de uma atenção para as mídias, bem como sua apropriação crítica e criativa, a partir da noção de mídia-educação que: 
é parte essencial dos processos de socialização das novas gerações, mas não apenas, pois deve incluir também populações adultas, numa concepção de educação ao longo da vida. Trata-se de um elemento essencial dos processos de produção, reprodução e transmissão da cultura, pois as mídias fazem parte da cultura contemporânea e nela desempenham papéis cada vez mais importantes, sua apropriação crítica e criativa, sendo, pois, imprescindível para o exercício da cidadania. (BÉVORT; BELLONI, 2009, p. 1083).

Nas disciplinas presentes na Educação Básica em contexto brasileiro, não existe uma responsável por tratar de sexualidade, corpo e gênero, mas, segundo as bases curriculares, tanto nacional quanto estadual, há especificada a importância de tratá-los, transversalmente, em todas as áreas do conhecimento. No entanto, quando lançamos um olhar mais minucioso para as propostas curriculares e até mesmo para os conteúdos dos livros didáticos, que inegavelmente ainda são ferramentas que perpassam e auxiliam a prática docente, as abordagens desses temas se limitam às áreas de Ciências e Biologia. Nesse sentido, há outra questão a ser levantada: como são, corriqueiramente, feitas essas abordagens? Furlani (2008) incentiva a repensar essas abordagens que têm se realizado de maneira normatizadora, determinista, excludente e biologizante. Nos cursos de licenciatura, a ausência de uma discussão mais ampla também tem se repetido e a tendência, em especial no curso de Biologia, que é de onde falamos, é de uma abordagem anatômico-fisiológica, sem enfoque para relações socioculturais, que são a base para o entendimento amplo das questões de sexualidade, corpo e gênero.

Alguns meios nos quais os temas serão tratados em sala de aula, em busca de abordagens que contemplem a relação desses temas na realidade dos alunos, são também apresentados nas bases curriculares, bem como na metodologia CTS (Ciência, Tecnologia e Sociedade). Nesse sentido, acreditamos que essas sejam formas positivas de motivar e chamar a atenção do aluno durante as aulas ministradas, o que proporciona uma melhor qualidade de seu aprendizado, em especial a metodologia CTS, por se tratar de uma abordagem que parte de assuntos presentes em seu cotidiano. Talvez pensar nos artefatos midiáticos, especialmente as séries, como voltados apenas para o lazer, ou algo que não pode trazer qualquer tipo de aprendizado significativo, não seja mais a questão, o que se deve fazer agora é buscar nessas séries formas e espaços de incentivar e enriquecer as discussões em sala de aula.

Tudo a nossa volta tem significado e, por consequência, traz um aprendizado. Para entendermos o mundo a nossa volta, necessitamos compreender os diversos significados das diversidades que nos cercam. Nesse caminho, torna-se necessária uma busca de aprendizados para além dos muros da escola. Em outras palavras, é necessário entender que há muitos conhecimentos envolvidos em tudo que faz parte do nosso cotidiano, e que eles estão entrelaçados com o que se é aprendido/trabalhado dentro do ambiente escolar.

Desde o Ensino Fundamental, os conhecimentos gerais nos são ensinados em forma de "matérias escolares", historicamente construídas e legitimadas (FERREIRA; SELLES, 2003), as quais são tratadas por blocos e dificilmente são integradas. Essa falta de integração, relacionada a um modus operandi de organização de conhecimento, não reflete a vida em suas facetas. Quando o assunto são as mídias e seus produtos, então, é mais que clara a falta de reflexo 
do mundo integrado na compartimentalização e disciplinarização dos conhecimentos escolares.

É um processo evidente que, aos poucos, as tecnologias, e falamos aqui especificamente das mídias, vão ganhando o espaço escolar. Porém, infelizmente, elas não são exploradas de formas mais amplas, pois ainda parecem presentes as dificuldades que professores enfrentam na realização de apropriações e propostas didáticas que fujam de práticas tradicionais de ensino. Assim, nesse trabalho propomos aprofundar a discussão das mídias que se inserem no cotidiano dos jovens e adolescentes, cujos produtos trazem diversos conceitos sobre assuntos, muitas vezes, não explorados das formas nas quais deveriam. É fato que o que é veiculado nas mídias tem uma pedagogia própria, pois gera aprendizados significativos sobre assuntos diversos, inclusive sobre os corpos, comportamentos e condutas. Por que, então, não utilizar pedagogicamente aquilo que é tão atrativo aos alunos? É, de certa forma, um retrocesso não conectar Educação em Ciências e as mídias, visto que elas estão presentes de modo tão significativo em nossas vidas.

Da mesma forma que os artefatos e conteúdos midiáticos podem ensinar, também podem confundir. Nesse sentido, se encontra a importância de os processos de ensino-aprendizagem articularem conteúdos a serem trabalhados em sala de aula, ao que é divulgado na televisão e/ou na internet. Contextualização e discussão constantes são fundamentais. Por serem temas contemporâneos sexualidade, corpo e gênero, suas abordagens se dão das mais diversas formas nos diversos meios supracitados, muito acessados pelos jovens e adolescentes em formação. Isso agrega maior relevância para que esses sejam estudados e analisados, a fim de se tornarem ferramentas de ensino-aprendizagem na formação de jovens e adolescentes. Os próprios professores de Biologia e Ciências também ganham, pois poderão explorar os conteúdos conceituais - para além de seus enfoques essencialmente biológicos, anatômicos e fisiológicos, abordando-os amplamente a partir de seus aspectos sociais.

\section{CAMINHOS METODOLÓGICOS}

Neste artigo nosso objetivo geral é trazer uma análise de como artefatos midiáticos populares entre jovens e adolescentes influenciam na construção de sentidos sobre sexualidade, corpo e gênero por esse público, a fim de compreendermos alguns possíveis discursos sobre tais temas. Vale ressaltar aqui que o presente artigo se trata de um pequeno recorte de uma outra pesquisa, mais ampla. Assim, nossas análises foram realizadas a partir da delimitação de um corpus. De acordo com Charaudeau e Maingueneau (2008):

nas ciências humanas e sociais mais particularmente, corpus designa o conjunto de dados que servem de base para a descrição e análise de um fenômeno. Nesse sentido, a questão da constituição do corpus é determinante para a pesquisa, pois trata-se de, a partir de um conjunto fechado e parcial, analisar um fenômeno mais vasto que essa amostra. (CHARAUDEAU; MAINGUENEAU, 2008, p. 137) midiático para pré-análise de delimitação desse corpus. Assim, optamos pelas 
séries, frequentemente acessadas pelo público alvo. A crescente popularidade do site Netflix, um canal pelo qual diversas séries, desenhos e filmes são disponibilizados, por um preço bem acessível por mês, torna a popularidade desse tipo de artefato ainda maior. A série escolhida foi uma estadunidense, a qual está em alta, com indicações ao Emmy - um outro tipo de premiação, semelhante ao oscar, mas que premeia as demais mídias televisivas - e se trata de uma série original Netflix. Dessa forma, a pesquisa foi feita no próprio site original da série. A série em questão se intitula "Orange Is The New Black", hoje com cinco temporadas e eleita, por muitos sites e blogs, como uma das melhores dez séries dos últimos tempos, o que confirma seu título de popularidade (além de pesquisas sobre audiência, como uma publicada em uma matéria no site Uol, neste ano, que mostra a série em sexto $\left.\operatorname{lugar}^{1}\right)$. Além de ser bem conhecida, sua classificação etária é para maiores de 16 anos, logo, ela se enquadra no público alvo desta pesquisa. Outro ponto, muito crucial, é o fato de que a série aborda muitos temas considerados como polêmicos/tabus, que estão intimamente relacionados aos temas do presente artigo (sexualidade, corpo e gênero).

A série possui muito conteúdo em suas cinco temporadas, porém, o recorte e delimitação do corpus para esse artigo envolve somente a primeira temporada, por já ser suficiente e conter todos os temas a serem trabalhados a partir da AD, em busca das possibilidades de construções de sentidos a partir de seu discurso. Todos os trechos cujos sentidos, em nossa leitura, se filiam a sexualidade, corpo ou gênero foram transcritos, fidedignamente, para posterior análise. Ao total, noventa e sete trechos foram transcritos, dos treze episódios que compõem a primeira temporada.

Para fins de análise, tais trechos foram agrupados nos temas "sexualidade", "corpo" e "gênero", com o intuito de condensar o trabalho e também buscar semelhanças ou diferenças nos discursos apresentados em diferentes momentos, por diferentes personagens. Portanto, os trechos foram cruzados para essas análises. Por se tratar apenas de um recorte de um trabalho maior, que traz a análise de outros trechos do total identificado, o presente artigo contará com um trecho somente, dentre todos que foram classificados, com sentidos que se filiam à sexualidade, corpo e gênero. Ou seja, serão analisados três trechos, dentro da totalidade (noventa e sete), um sobre corpo, outro sobre gênero e, por fim, um sobre sexualidade.

Como possibilidade teórico-analítica para estudar os processos de construção de sentidos acerca dos temas sexualidade, corpo e gênero, como já citado ao decorrer do texto, a AD será o principal referencial desta pesquisa. Assim, a $A D$ parte da ideia de que os sentidos são produzidos durante um discurso, o qual não existe sem um locutor, que por sua vez é um sujeito histórico (ORLANDI, 2003). Logo, a AD será usada para a análise, por se tratar de uma análise de sentidos construídos e constituídos em um discurso, o qual está inserido em um contexto sócio-histórico repleto de ideologias, que também devem ser levados em consideração. Tais pontos devem ser levados em consideração, principalmente ao se analisar uma mídia, visto que o próprio termo já é bastante polissêmico, ou seja, possibilita diversas construções de sentidos e significados. A esse respeito, o simples fato de mais de uma pessoa construir uma notícia, no caso de um telejornal, por exemplo, já carrega/agrega vários sentidos, desde a fonte, de quem apresentou o fato, passando pela equipe responsável por montar as notícias, até 
chegar a quem vai apresentá-la. Aí, o sentido inicial já não é o mesmo, visto que são pessoas diferentes, que fazem parte de contextos sociais distintos e, até mesmo, com ideologias divergentes (RAMOS, 2006). Partindo dessas duas ideias principais, o presente artigo foi redigido.

\section{RESULTADOS E DISCUSSÃO}

Neste artigo, dos noventa e sete trechos transcritos da primeira temporada da série Orange Is The New Black, apenas três foram trazidos para fins de análise. Além desses trechos, há captura de tela de algumas cenas, que são cruciais para análises complementares, já que, na perspectiva discursiva, o texto imagético também contempla diversos discursos. Com fins de ampliar a compreensão dos leitores deste artigo, será apresentado um resumo da série, bem como a ideia principal da mesma, antes das análises propriamente ditas.

Conforme já mencionamos, o referencial teórico-metodológico usado para a análise dos trechos constituintes do corpus é a AD. Essa, por sua vez, se constitui como um referencial teórico-metodológico que inclui questões sociais, históricas e até mesmo ideológicas, pois um discurso é escrito/falado por alguém para outrem, o que implica muitos outros elementos relacionados ao texto/fala, além da própria transmissão de ideias. Nas palavras de Orlandi (2003), “(...) não há discurso sem sujeito. E não há sujeito sem ideologia".

A série é narrada a partir de uma personagem principal, uma moça chamada Piper Chapman, que foi condenada a uma pena de 15 meses em uma penitenciária de segurança mínima, denominada Lichfield, por carregar uma mala cheia de dinheiro de narcotraficantes. Na época, Piper era uma jovem universitária que estava em busca de novas aventuras, então conhece Alex Vause, uma narcotraficante que morava na universidade, e acaba se relacionando com ela, o que leva Piper a carregar a tal mala de dinheiro. Com o decorrer do drama de Piper, histórias de outras presas, que estão em um contato maior com a personal principal, são relatadas, em forma de lembranças delas, e trazem explicações de como foram parar em Lichfield. Dentro da prisão, as detentas são chamadas por seus sobrenomes e todas possuem um orientador, sendo o de Chapman o senhor Healy. As detentas fazem todos os serviços da prisão, sendo supervisionadas por guardas, 24 horas do dia.

Partiremos agora para as análises propriamente ditas dos três trechos selecionados. Primeiramente apresentaremos os sentidos por nós identificados nos trechos, acerca dos temas sexualidade, corpo e gênero. Posteriormente, trataremos de exemplos/formas de se apresentar e estudar tais sentidos identificados, nos atendo às possíveis influências nos processos de construção de sentidos sobre tais temas, ou seja, à condições de produção desses sentidos. Tal sequência foi assim pensada como uma estratégia para enriquecer o Ensino de Ciências, quando tratada a educação sexual em sala de aula.

O primeiro trecho, correspondente à figura 1 , traz sentidos e compreensões sobre sexualidade, e está no primeiro episódio da primeira temporada. Esse episódio aborda grande parte da história de Chapman, pois a série inicia com sua rendição e durante o período em que Larry, seu noivo, a leva até Lichfield, vários flashbacks sobre os últimos dias de Piper, ainda livre, aparecem, bem como seu 
primeiro dia de prisão, que foi muito conturbado. O trecho que será analisado começa em 11' (onze minutos) e acaba em 12 (doze minutos), e mostra como foi para Piper contar à família que seria presa:

Figura 1 - Familiares de Piper (da esquerda para a direita: pai, mãe, avó e irmão)

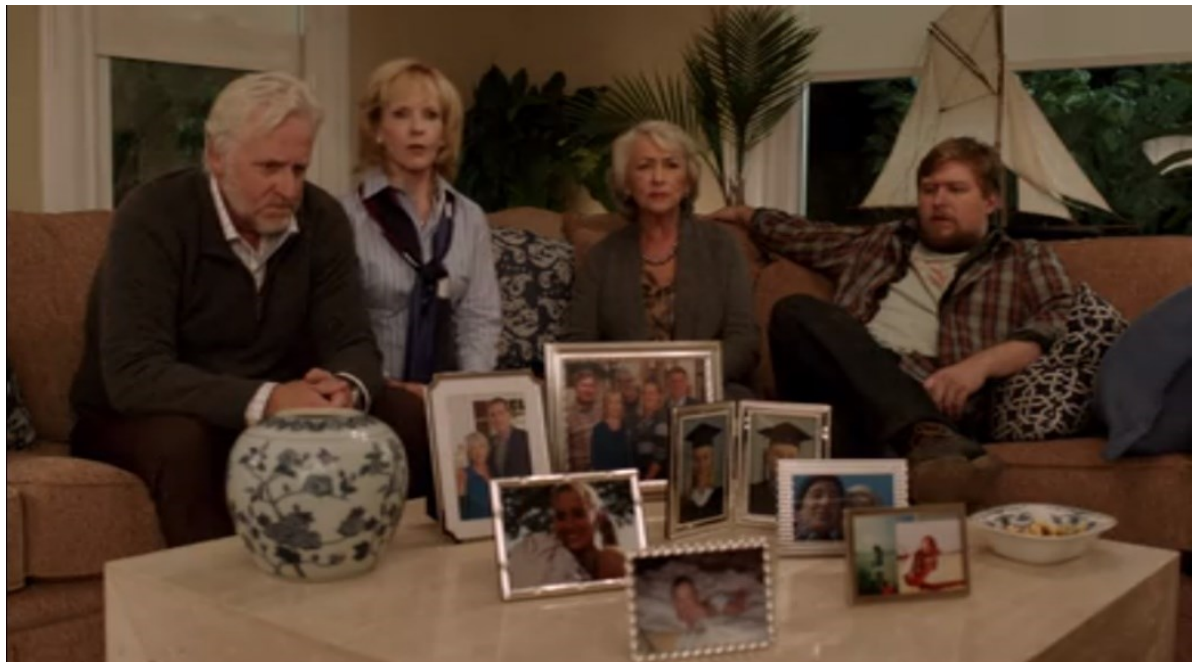

Fonte: captura de tela - Netflix, Orange Is The New Black, episódio 1, temporada 1.

“Piper: ‘Eu nunca transportei drogas, só dinheiro’;

Mãe Piper: 'Você era lésbica?';

Piper: 'Na época';

Irmão Piper: 'E ainda é?';

Piper: 'Não, eu não sou mais lésbica';

Noivo Piper (Larry): 'Tem certeza?';

Piper apenas suspira;

Avó Piper: 'Uma vez eu beijei Mary Strailler na escola da Srta. Potter, mas não era pra mim';

Irmão Piper: 'Nossa (voz surpreso)';

Pai Piper pergunta a Larry: 'Você sabia disso?';

Larry: 'Não, não, não, eu não sabia. Ela me contou das viagens depois da faculdade, mas ela não mencionou a amante lésbica que era traficante internacional, imaginem a minha surpresa (toda a fala em tom nervoso)';

Todos estão com cara de decepcionados. Avó Piper pergunta: 'E o que você fez com todo esse dinheiro?';

Piper responde, em tom provocativo: 'A questão, vovó, é que eu não tava interessada no dinheiro';

Avó, indignada: 'Oh, Piper! Pelo amor de Deus!'; 
Na fala inicial de Piper: "Eu nunca transportei drogas, só dinheiro", destacamos, de acordo com a $A D$, a noção de interdiscurso. Quando ela se refere ao fato de ter cometido um crime, já o menciona de forma a amenizar seu relato, pois, talvez, o que ela esperava como resposta de seus familiares seria uma reação um tanto horrorizada, devido à posição social ocupada por uma pessoa envolvida com o tráfico de drogas. $O$ interdiscurso aqui se liga com a memória discursiva, pois o interdiscurso só existe porque o que estamos dizendo faz sentido por ter sido dito antes. Em outras palavras, Piper se colocou no lugar de quem a ouvia, isso, na $A D$, é chamado de mecanismo de antecipação, quando o sujeito se coloca na posição de seu interlocutor, ou seja, a fala é realizada de tal forma por conta de expectativas prévias. Nesse caso, a família de Piper é de classe alta e tradicional, então ela traz seu discurso de forma a amenizar o crime cometido, pois sabe que o traficar é algo errado legalmente, e também socialmente (memória discursiva), dizendo que apenas transportou dinheiro, não drogas, que seu crime não foi tão grave quanto parece.

O que ela recebe, porém, em resposta de sua mãe é "Você era lésbica?", seguido de um "E ainda é?", de seu irmão, e um "Tem certeza?", de seu noivo. As próximas falas também giram ao redor do fato de Piper ter uma ex-namorada. Aqui, pudemos notar um silenciamento por parte de Piper, pois ela nunca havia mencionado a seus familiares o fato de já ter, um dia, namorado uma mulher. 0 silenciamento, para Orlandi (2007, p. 31), é uma forma de dizer, pois ele traz sentidos, mesmo não ditos. Nas palavras dessa autora "O silêncio é. Ele significa. Ou melhor: no silêncio, o sentido é".

Ao omitir essa parte de sua vida, Piper queria, possivelmente, evitar os comentários que escutou, todos transcritos no primeiro trecho, comentários esses negativos sobre o fato, mas que, ao final do trecho, são rebatidos por Piper, em sua última fala: "A questão, vovó, é que eu não tava interessada no dinheiro". Se analisarmos a figura 1, podemos perceber a cara de decepção de todos os presentes na sala, e chegar a três possíveis sentidos: a decepção é causada pela prisão em si ou é causada pelo fato de Piper já ter sido lésbica ou ainda a junção das duas coisas (porém, pelo discurso apresentado, que envolve apenas falas relacionadas à antiga relação amorosa de Piper, provavelmente o segundo sentido construído é o que mais aponta ao relatado). Nessa análise apontamos duas filiações de sentidos, em relação à homoafetividade/homossexualidade: uma relacionada a não aprovação social de seu relacionamento, principalmente presente no discurso imagético da Figura 1. Assim, tal discurso pode remeter, até mesm, ao crime por ela cometido, algo presente na fala de seu noivo Larry, ao proferir “(...) a amante lésbica que era traficante internacional”. Em contrapartida, outra filiação de sentido, relacionada ao aspecto passional, foi por nós identificada na fala de Piper, quando seu discurso remete ao fato de estava com Alex (sua exnamorada), porque a amava e cometeu tal crime por isso.

Ainda em relação ao primeiro trecho, discursivamente levantamos novamente a antecipação de Piper ao silenciar o fato de já ter tido uma namorada, pois Piper se colocou no lugar das pessoas que não compreenderiam suas escolhas afetivas e isso é muito comum. Muitos discursos de ódio são proliferados, quase que todos os dias, por diversos meios de comunicação, sejam eles virtuais ou pessoais e isso é notável no dia-a-dia. Analisando historicamente o fato, relações homoafetivas eram vistas como algo abominável, as pessoas que se relacionavam 
assim eram ditas doentes pela medicina, pecadoras pela teologia e criminosas perante a lei (FREIRE; CARDINALI, 2012). Felizmente, com os Direitos Humanos e a uma mudança na cultura da sociedade - isso em relação aos tabus, crenças, preconceitos etc. - hoje a concepção homossexual passou por mudanças, no seu estilo de ser e estar, ampliando suas inserções na sociedade, porém, a homofobia ainda é muito presente na vida dessas pessoas (NASCIMENTO, 2010). Todos esses fatos mencionados já existiam, estavam lá e apontavam para outros sentidos e discursos. Piper, ao se antecipar, esperando falas parecidas com as que ouviu, silenciou-se, pois já sabia desses sentidos pré-construídos, os quais poderiam aparecer nas falas deles - interdiscurso.

O segundo trecho, representado na figura 2, está presente no terceiro episódio e traz questões relacionadas ao gênero. Dentre as presas de Lichfield nome que recebe a penitenciária em que toda a trama é desenrolada - existe uma mulher transgênero, de nome Sophia Burset. Sophia foi presa por fraudar cartões de crédito (fato esse possível de se perceber no desenrolar do terceiro episódio, incluindo um momento no presente trecho). $O$ trecho em questão é uma memória de Sophia, antes de ser presa, ela está em uma loja de calçados com seu filho Michael, para comprar um tênis novo para o garoto. $O$ trecho se inicia no tempo $33^{\prime 2} 20^{\prime \prime}$ (trinta e três minutos e vinte segundos) e termina em 34'40" (trinta e quatro minutos e quarenta segundos):

Figura 2 - Sophia, Michael, vendedor (agachado) e Pet, em sua chegada

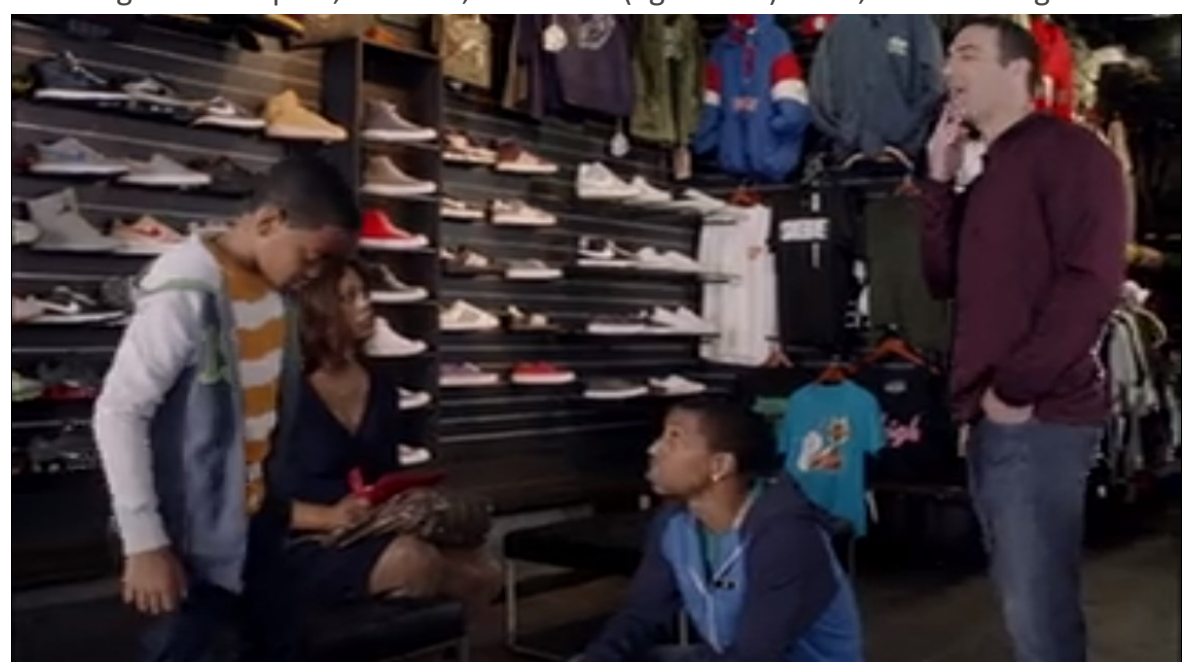

Fonte: captura de tela - Netflix, Orange Is The New Black, episódio 3, temporada 1.

"O vendedor diz ao garoto: 'Se quiser passar por isso, eu recomendo o Jordan';

Sophia: 'É maneiro';

Michael: 'É muito gay. Gosto do Le Bron';

Vendedor: 'Cano alto ou baixo?';

Michael: 'Os dois';

Sophia: 'Não, escolhe um, filho'; 
Vendedor: 'Se tiver que escolher, cara, recomendo o cano baixo, é muito irado, é o tênis mais maneiro lançado esse ano';

Sophia: 'E quanto custa?';

Vendedor: '300 (trezentos)';

Michael a olha e diz: 'Vamo leva, né?!';

Enquanto ela abre a carteira, Michael avista a dezena de cartões de crédito que Sophia tem e então os dois se olham, Sophia tem um olhar de culpa;

Vendedor: 'Levanta aí cara, anda um pouco, você vai adorar esse tênis';

Um conhecido de Sophia e Michael aparece na loja, e vai até o vendedor, é quando reconhece Michael: 'Com licença, você tem... Oi, Michael! O que que você tá fazendo aqui?';

Eis que o conhecido avista Sophia e fica surpreso: 'Que isso!';

Sophia: 'Como vai, Pet?';

O moço fica sem jeito e muito desconfortável, gaguejando, então Sophia diz: 'Pois é';

O rapaz gagueja mais um pouco e diz: 'A Débora tá fazendo compras e eu resolvi...';

Sophia o interrompe: 'Você recebeu minha carta? Eu queria ter notícia sua';

Pet: 'É, eu tava... É, desculpa, eu tenho que ir' e então se retira;

Sophia olha para Michael, que está super bravo, e Pet diz: 'Se cuida, Michael! Tênis maneiro, hein?!';

Michael não diz nada e Sophia então tenta mudar de assunto, indo falar com o garoto, um tanto sem graça: 'Pra algumas pessoas é difícil...';

Michael levanta e chuta uma pilha de sapatos que está na porta da loja e sai, Sophia o chama e o repreende pela ação, mas ele vai embora;

Vendedor: 'Senhor... Senhora, tem que pagar pelo tênis';

Sophia está quase chorando." (Trecho 2, grifos nossos)

Esse trecho aponta para a temática gênero, salvo uma fala de Michael: no início da cena que mostra uma das lembranças de Sophia, o menino está falando com o vendedor, que está Ihe ajudando a escolher o melhor tênis. Quando o vendedor diz para que ele escolha um determinado calçado, Michael já diz "É muito gay" e prefere um outro tênis. Ao proferir tal frase, o garoto parece conferir ao termo gay um novo sentido, na $A D$ essa ressignificação de um termo é denominada polissemia, onde há uma ruptura no processo de significação. Essa polissemia se faz possível caso a história seja passível de ruptura, ou seja, ao decorrer dos fatos históricos em uma sociedade, um termo pode receber um novo significado, dependendo do novo contexto inserido. A palavra gay vem do inglês e significa alegre, tendo origem também do português gai, com significado parecido, e desde o século 13 é usada como sinônimo de homossexual, sendo que, há mais 
de três décadas foi incorporada pelos próprios homossexuais como designação para si próprios (POSSENTI, 1995). Em diversos meios, incluindo o ambiente escolar, o termo gay é muito utilizado com esse mesmo sentido que Michael traz, de forma pejorativa, e isso vem da história e cultura de toda uma sociedade, como já discutido anteriormente, devido a forma como homens homossexuais eram vistos antigamente - e muitas vezes ainda são na atualidade, como também já citado. Em âmbito escolar, segundo Roselli-Cruz (2011) “(...) alguns alunos podem sofrer um tipo de bullying com o xingamento e com a representação de seus atos motores, gestos e fala estereotipada, que caracteriza um tipo de bullying homofóbico".

Partindo agora para o tema gênero em si, o segundo trecho traz o reencontro de Sophia com um velho amigo, Pet, que, ao avistá-la, ficou totalmente sem saber o que fazer, proferindo, até mesmo, a seguinte frase, como se tivesse tomado um susto ao se deparar com Sophia: "Que isso!". Com essa fala do personagem Pet, percebemos o que na $A D$ é chamado de esquecimento ideológico, que nada mais é do que algo intrínseco, algo inconsciente, pois nascemos inseridos em um discurso pronto. Ou seja, ao dizer "Que isso!" quando avistou Sophia, o homem apenas parafraseou sentidos de um discurso com o qual se identifica, mesmo que inconscientemente - de que um transgênero é algo assustador, errado, algo que não faz parte de seu meio. Nesta análise, achamos também importante salientar o alcance que uma transexual em uma série tão vista como Orange Is The New Black pode atingir. Segundo um levantamento do Grupo Gay da Bahia (GGB), em 2015, 134 transgêneros foram mortos no Brasil e segundo a ONG internacional Transgender Europe o Brasil é o país que mais mata essa parcela da população e nem todos os casos são registrados (LEITE, 2016).

Ainda em relação ao segundo trecho, a fala de Sophia e Pet que, onde o conhecido de Sophia gagueja muito, a fim de quebrar aquele momento um tanto constrangedor, ela o questiona sobre uma carta que enviou e o que Sophia recebe de resposta é "É, eu tava... É, desculpa, eu tenho que ir". Aqui pudemos notar outro silenciamento, que, segundo Orlandi (2007) é "o silêncio fundador, aquele que existe nas palavras, que significa o não-dito e que dá espaço de recuo significante, produzindo as condições para significar". Ou seja, ao questionar Pet porque ele não a respondeu por todo esse tempo, e esse hesitar, deixando-a sem uma resposta propriamente dita, parece emergente esse silêncio fundador, que atua na significação de algumas coisas para Sophia, como a não compreensão por parte de Pet sobre a mudança que ela sofreu. Isso é possível perceber na própria fala de Sofia, quando Pet vai embora e ela diz a Michael "Pra algumas pessoas é difícil..." - que tanto é uma compreensão no sentido de falta de informações sobre o caso, como de preconceito, mas, no sentido ideológico, de que isso é errado e causa uma certa vergonha em Pet, o que o leva a se esquivar em sua resposta.

Sobre esse segundo trecho ainda, o fato de que Michael sai correndo após o encontro com Pet na loja de calçados também traz um significado: o garoto não aceita o fato de Sophia ser uma mulher transexual e tem vergonha disso, o que o deixa muito irritado, como ilustra a figura 3 , momentos antes de sua fuga: 
Figura 3 - Momentos antes de Michael sair correndo da loja de calçados, encarando com raiva Sophia

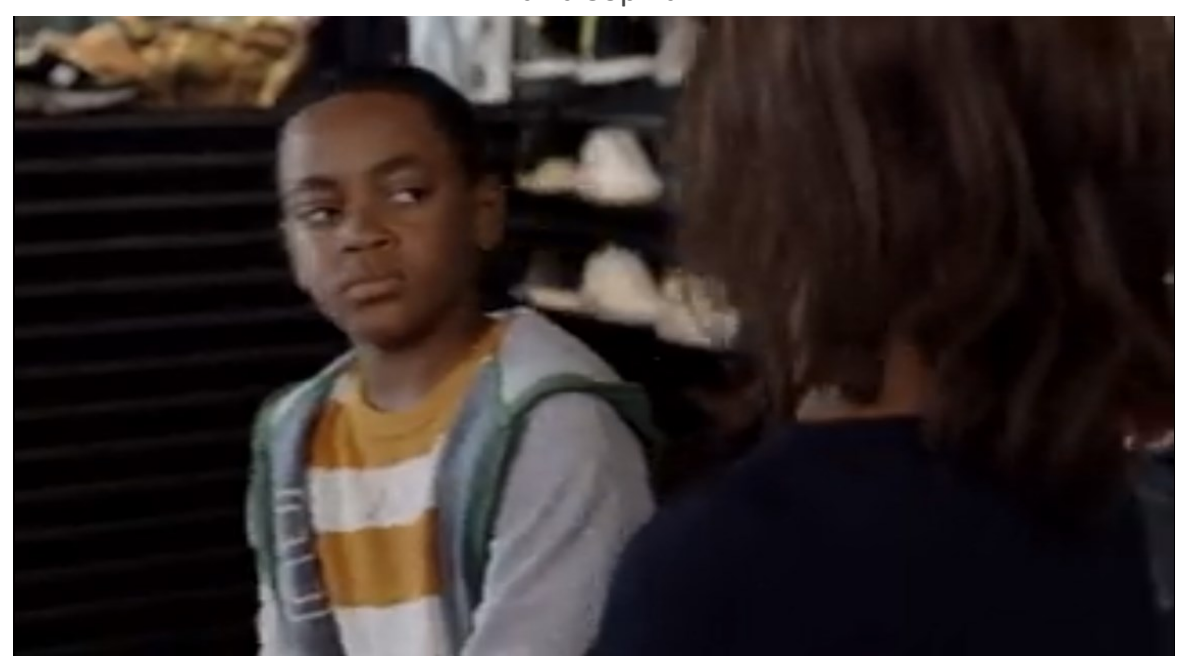

Fonte: captura de tela - Netflix, Orange Is The New Black, episódio 3, temporada 1.

Antes da transição, Sophia era Marcus, um bombeiro. Nas cenas iniciais desse mesmo episódio (três), cenas de Marcus no vestiário são relatadas, onde mostram ele, ao retirar sua camisa, revelar um sutiã cor de rosa. Em outras lembranças de Sophia ao decorrer do episódio, Crystal, sua esposa, aparece, auxiliando Sophia com suas novas roupas. Sophia tem uma família, teve um filho com Crystal antes da transição. Dentre uma gama de sentidos, que depende das histórias de leitura e do contexto sócio-cultural de cada espectador, de maneira generalizada e alinhada às condições de produção amplas de alguns discursos de nossa sociedade, apontamos alguns que podem ser construídos a partir dessas cenas: o primeiro, como já dito, é o sentido da não aceitação da parte de Michael, e o segundo é o de apoio que Crystal dá a Sophia, ao ajudá-la. Muitos casos de ódio e não aceitação por parte da família são observados nos casos de transgêneros, mas também há vários outros casos de aceitação e apoio, vindo também por parte dos entes queridos. Mostrar esses dois lados durante a série é crucial, pois ilustra, mais uma vez, como é para a pessoa transgênero viver da forma como sempre quis e nasceu para ser.

Em relação ao final desse segundo trecho, mais especificamente sobre a última fala do vendedor, referindo-se a Sophia, porque Michael saiu correndo da loja, calçando o tênis que queria comprar: "Senhor... Senhora, tem que pagar pelo tênis". Ao se "confundir" em como chamar Sophia, dois pontos teóricos podem ser levantados, segundo a AD: o primeiro seria, novamente, o esquecimento ideológico, identificado por nós pelo rapaz chamar Sophia de senhor, quando ele então percebe que ela é uma mulher transexual. Aqui entra um problema recorrente na vida dos trans numa sociedade fudamentada na ideia heteronormativa, em que existe apenas o binarismo macho-fêmea, relacionado ao sexo que a pessoa nasceu (BARBOSA; SILVA, 2015). Ou seja, nessa ideia, Sophia será sempre "ele", pois nasceu homem, sem espaço para o gênero com o qual se identifica; e o segundo ponto teórico é a formação discursiva, a posição que o sujeito que escuta tem em relação ao sujeito que fala. Nesse caso, nas falas iniciais, o vendedor tratava Sophia de uma forma, como aparenta ser: mulher e, após perceber que ela é uma mulher transexual, o jeito como ele passa a se referir a ela 
muda totalmente, pois o modo como Sophia é vista pela sociedade é como uma pessoa inferior aos demais, repleto de preconceitos e discriminação.

O terceiro e último trecho, juntamente com a Figura 4, presente no tempo $41^{\prime} 25^{\prime \prime}$ (quarenta e um minutos e vinte e cinco segundos) a 42'20" (quarenta e dois minutos e vinte segundos) do quarto episódio da primeira temporada, traz o tema corpo. Essa passagem é uma lembrança da detenta Claudette Pelage, uma senhora que, quando adolescente, deixou seu país de origem, o Haiti, e foi para Nova York, a fim de pagar as dívidas de seus pais, trabalhar como doméstica em uma casa destinada para isso - nessa casa vivem muitas outras meninas que estão ali para o mesmo fim que Claudette e são monitoradas por uma mulher, que recebe as novas garotas. Quando adulta, Claudette tomou o lugar de monitora das meninas e passou a ser conhecida como senhorita Claudette (do inglês da série, Miss Claudette), então passou a cuidar e receber as novatas. A lembrança retratada no trecho em questão envolve senhorita Claudette e a indisciplina, aparentemente, de uma das novatas:

Figura 4 - Novata da casa da senhorita Claudette mostrando seus hematomas

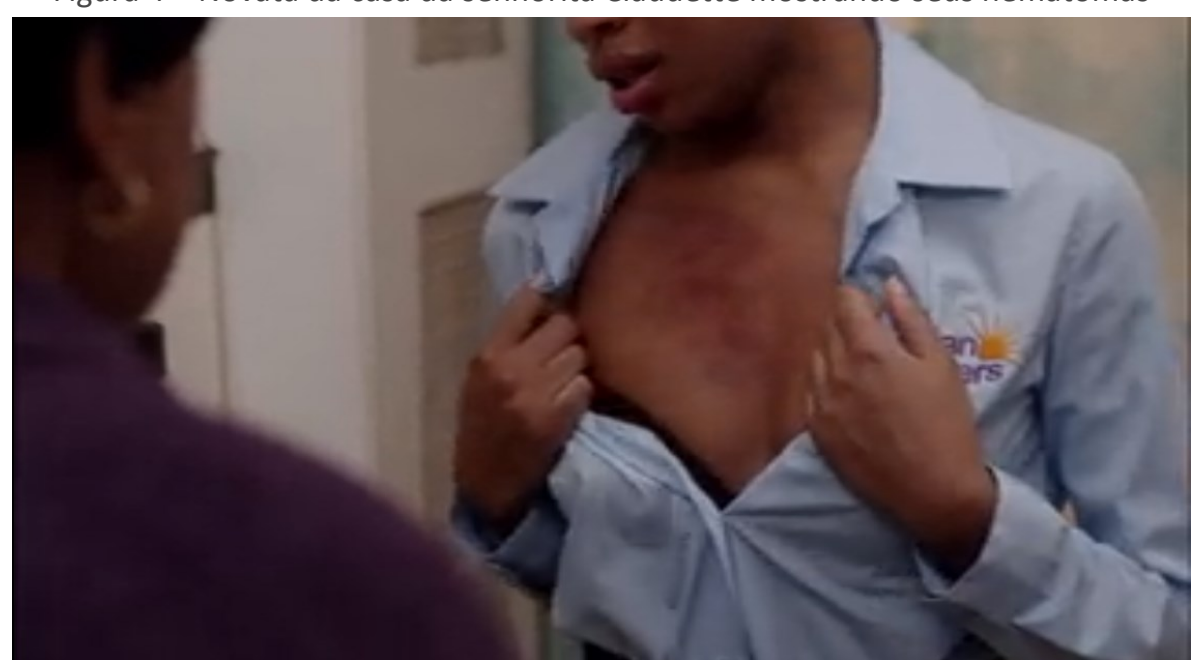

Fonte: captura de tela - Netflix, Orange Is The New Black, episódio 4, temporada 1.

“Claudette está falando com a novata: 'Ouviu o que eu disse? Todas devem tomar banho! Você entra lá, tira a roupa e toma um banho agora!';

A menina não se mexe;

Claudette: 'O que tá acontecendo? Menina, se explica!';

A menina apenas abaixa a cabeça;

Claudete diz para as demais meninas que estavam ali: 'Podem sair';

Então ela leva a menina até o banheiro e fecha a porta, então pergunta: ‘O que aconteceu com você? Pode falar pra mim';

A menina começa a chorar, em seguida começa a se despir e mostra as manchas roxas que tem espalhadas pelo corpo. Senhorita Claudette fica horrorizada." (Trecho 3, grifos nossos) 
A cena pode ser analisada pelo viés do tema corpo, pois se trata de um caso de abuso, violência contra mulher. O principal constructo percebido nesse trecho é o silêncio. Durante toda a fala de senhorita Claudette, a menina novata não profere uma só palavra. Antes de as duas entrarem no banheiro, como mostra a Figura 4, a garota permanece calada e apenas faz contato visual com Claudette, como mostra a Figura 5:

Figura 5 - Novata na casa de senhorita Claudette sem proferir uma só palavra

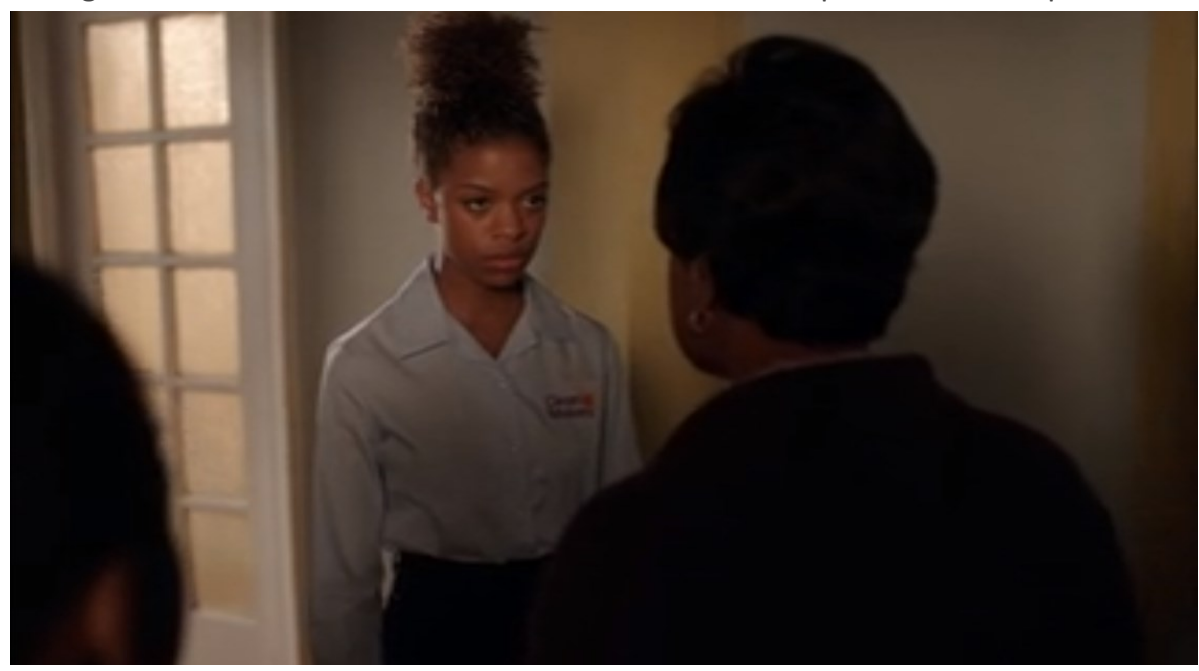

Fonte: captura de tela - Netflix, Orange Is The New Black, episódio 4, temporada 1.

O silêncio, nesse caso, é o local, que, nas palavras de Orlandi (2007) é “(...) que se refere à censura propriamente (aquilo que é proibido dizer em uma certa conjuntura)". Ou seja, a menina não disse nada, porque há um discurso, já existente, de que ser abusada e/ou violentada é motivo para censura, pois é causa de vergonha para ela, a vítima, caso seja relatado perante outras pessoas. Para a moça, já foi motivo de vergonha, por precisar mostrar à senhorita Claudette, como retrata a Figura 4. No momento em que ela está levantando sua blusa, para mostrar os hematomas que estão por todo o corpo, ela vira seu rosto, evitando contato visual com Claudette.

É aqui que entra a importância de se tratar assuntos como a violência doméstica e o abuso de menores, novamente, em um meio popular como essa série. Em casos de estupro, por exemplo, muitas vítimas não vão até os órgãos maiores, como a polícia, para fazer o boletim de ocorrência. Isso é uma decorrência do fato que, na maioria das vezes, elas são julgadas por terem sido abusadas, a frequente culpabilização da vítima, que, durante o interrogatório da queixa, são obrigadas a ouvir perguntas como "Que roupa você estava usando?" e se o caso tiver ocorrido à noite, ainda escutam "Fora de casa a uma hora dessas, só podia dar nisso mesmo". Outro exemplo de violência contra mulher é a doméstica, que também é, muitas vezes, escondida ou apenas "esquecida" (trazemos o termo entre aspas, visto que as consequências psicológicas não permitem que tal fato seja, realmente, esquecido). Nesse outro caso a vítima também é culpabilizada, visto que muitos dos argumentos proferidos por quem é apenas espectador do fato são do tipo "Ela gosta de apanhar, por isso ainda tá com ele", porém, muitas vezes, o agressor ameaça a vítima, caso ela tente tomar alguma providência quanto ao caso. Felizmente, com a Lei Maria da Penha, os casos de violência 
doméstica, hoje, são levados a sério pelas autoridades, os agressores são detidos e o caso não é deixado de lado, como nos casos de estupro, que muitas vezes não é feito nada contra o agressor e o atendimento a mulher é apenas um exame de DNA, para a coleta de dados, e amparo psicológico (FAÚNDES et al., 2006).

\section{ALGUMAS RELAÇÕES E CONSIDERAÇÕES}

Trazendo agora de forma mais concreta a discussão das implicações dessa mídia na Educação em Ciências, faremos a seguir algumas considerações sobre como os trechos analisados podem ser utilizados pelo professor de Ciências e/ou Biologia em suas aulas. Os livros de Ciências e Biologia, na maioria das vezes, não abordam de forma ampla os temas sexualidade, corpo e gênero. A educação sexual, nos livros didáticos, é apresentada, para o Ensino Fundamental, apenas no oitavo ano, quando o assunto corpo humano é trabalhado, e aparece apenas no estudo do sistema reprodutor, o qual, muitas vezes, encontra-se ao final do livro ou os professores deixam para trabalhar mais para o final do ano. Quando ele é trabalhado, muitas vezes, é trazido de uma forma, como Furlani (2008) classifica, biológica-higienista:

é aquela, por muitas/os, considerada a prevalente (e até mesma a única) nas ações educacionais voltadas à discussão do desenvolvimento sexual humano no contexto, sobretudo, da escolarização formal. Costuma conferir ênfase na biologia essencialista (baseada no determinismo biológico) e é marcada pela centralidade ao ensino como promoção da saúde, da reprodução humana, das DSTs, da gravidez indesejada, do planejamento familiar, etc. Por manter inquestionáveis as premissas acerca do determinismo biológico, considera as diferenças entre homens e mulheres decorrente dos atributos corporais - o que contribuiu (e contribui), tanto para 'naturalização' das desigualdades sexuais e de gênero, quanto para a formulação dos enunciados que hierarquizam essas diferenças (como, por exemplo, premissas machistas, sexistas misóginas e homofóbicas). (FURLANI, 2008, p.19)

É dessa forma, biológica-higienista, que o livro didático tem seus conteúdos estruturados, na maioria das vezes (senão todas) - começando por Doenças Sexualmente Transmissíveis (DSTs) e terminando nos métodos contraceptivos e a gravidez na adolescência. Como a própria autora aborda no trecho anterior, podemos descartar a relevância de se tratar desses temas, porém, há problemas quando apenas dessa forma a educação sexual é trabalhada em sala de aula. Mostrar aos alunos como são seus corpos, como eles funcionam, que existem doenças sexualmente transmissíveis, e que elas podem ser graves, e que uma gravidez no início de suas vidas sexuais pode ser algo indesejável, por vários fatores, é importante. No entanto, também é importante mostrar a diversidade que a sexualidade apresenta. É importante sair dessa heteronormatividade que nos cerca, mostrar que existem pessoas homossexuais e que isso é natural, sempre existiu, e que, inclusive, existe (e é frequente) em outras espécies animais, por exemplo.

Ainda sobre os livros didáticos, caso seja feita uma análise breve (algo como abrir nas páginas dedicadas à educação sexual) de como são dispostos os conteúdos conceituais de Biologia do Ensino Médio (EM), por exemplo, pode-se perceber que, na maioria das vezes, a educação sexual não foge muito do que já fora supracitado, o que se aproxima da abordagem biológica-higienista, porém, a 
diferença é que o foco é maior para a reprodução humana. Os livros trazem o assunto atrelado à embriologia, visto que apenas no EM os alunos têm contato com o desenvolvimento embrionário. Mais uma vez o discurso não aponta para a diversidade da sexualidade, pois seus sentidos apontam apenas para reprodução, homem e mulher, a heteronormatividade, que contribui para as desigualdades sexuais e, por consequência, para discursos homofóbicos, como Furlani (2008) traz no trecho supratranscrito.

Em relação aos temas corpo e gênero, esse discurso segue o mesmo padrão, já que a autora também cita as desigualdades de gênero e as premissas machistas. Muitos livros ilustram o assunto educação sexual com o corpo de um homem, seja para introduzir o assunto, ou seja para os métodos contraceptivos - geralmente, quando os preservativos são citados, o masculino é o único ilustrado, isso quando não é o único mencionado. Uma forma, então, de mudar essa abordagem dos livros e ir além, poderia se dar por meio de materiais de outras fontes, que tratem sobre sexualidade, corpo e gênero e que apontem para sentidos mais amplos e menos normatizadores.

Assim como Ramos (2006), também percebemos que é possível se aprender com as mídias. No entanto, no caso deste artigo, buscamos pontuar como uma série, muitas vezes utilizada apenas como um meio de lazer por jovens e adolescentes, pode influenciar na construção de sentidos sobre sexualidade, corpo e gênero. Como caminho, apontamos a possibilidade de se levar os trechos pré analisados até a sala de aula, a fim de contextualizar aulas que tenham como foco promover a educação sexual, visando proporcionar ao aluno que ele tenha uma maior criticidade perante alguns assuntos. Por exemplo, no primeiro trecho analisado, que mostra como foi para Piper contar a sua família que seria presa, notamos que o principal do assunto não fora o crime em si, mas sim o fato de que Piper já teve relações homoafetivas. Percebemos dois sentidos quanto a isso: a família enxergar a homossexualidade como algo negativo, com todo o discurso apresentado, e o lado de Piper, que apenas seguiu suas vontades. Esse trecho se adequaria bem a um trabalho do assunto sexualidade com os alunos, que fugiria bastante da abordagem tradicional biológica-higienista e entraria na abordagem dos Direitos Humanos:

é aquela que fala, explicita, problematiza e destrói as representações negativas socialmente impostas a esses sujeitos e às suas identidades 'excluídas', num processo educacional que é assumidamente política e compremetido com a construção de uma sociedade melhor, menos desigual, mais humana - na totalidade semântica desse termo. (FURLANI, 2008, p.26)

Ou até mesmo na abordagem dos Direitos Sexuais:

Falar em Direitos Sexuais para o movimento GLBTTT é... Alterar o contexto social que promove a exclusão social, a homofobia, a lesbofobia e a discriminação sexual. Garantir a visibilidade da diferença é uma estratégia mundial (as passeatas do Dia do Orgulho Gay - 28 de junho; no Brasil, o dia do Orgulho Lésbico - 19 de agosto), bem como a aparição na mídia, em eventos culturais, em processos políticos em eleições (lançando candidatas/os), forçando o 'assumir' público de celebridades e artistas (para aquelas facções mais radicais do movimento). (FURLANI, 2008, p.29)

Pensamos que uma forma mais ampla de abordar o assunto sexualidade seja possível a partir da junção dessas duas abordagens. Por exemplo, com o trecho 
número um do presente artigo, é possível explicitar e problematizar a situação, trazendo as duas visões acerca do assunto, negativa e positiva, buscando confrontar as formações preexistentes e estimular os estudantes a que pensem sobre o assunto. Então, em conjunto com as abordagens dos Direitos Humanos e dos Direitos Sexuais, se faz possível garantir, assim, tanto a visibilidade dessa parcela da população que, muitas vezes, sofre com a homofobia, quanto a oportunidade de que os jovens e adolescentes construam uma criticidade maior perante $o$ assunto.

A mesma abordagem dos Direitos Sexuais entra quando falamos de gênero e corpo, podendo, também, abordar tais assuntos com a ajuda dos trechos dois e três, respectivamente. Dois trechos no livro de Furlani (2008) resumem bem o porquê dos dois assuntos encaixarem também na abordagem citada, sendo que o primeiro fala da regulamentação da lei de redesignação de sexo, bem como do registro civil, para transexuais, luta essa que está na agenda GLBTTT²:

\footnotetext{
Até o ano de 1997, no Brasil, era proibida a cirurgia de mudança de sexo. Naquele ano, o Conselho Federal de Medicina, através da resolução 1482/1997, regulamentou as condições para a cirurgia transgenital e definiu aspectos legais e éticos, atrelando-a somente aos hospitais universitários (hospital-escola) a título de pesquisa científica, sem o caráter financeiro. Hoje, após a cirurgia, processos judiciais específicos, visando a alteração do registro civil, permitem que transexuais obtenham nova carteira de identidade com nome adequado ao novo sexo e ao novo gênero. (FURLANI, 2008, p.29)
}

A partir do trecho da memória de Sophia Burset e os sentidos nele percebidos, e partindo do preconceito vivido por ela, uma discussão acerca dos direitos das pessoas transexuais pode ser feita em sala de aula, juntamente com o trecho transcrito acima, a fim de promover o respeito e uma compreensão da importância de se tratar tal assunto.

Furlani (2008) também traz um trecho discorrendo a importância de se tratar sobre a violência contra a mulher:

\footnotetext{
Mas os desafios da sociedade e das políticas públicas, voltadas a outras conquistas para as mulheres, são muitos e continuam. Por exemplo, a denúncia e combate das muitas formas de violência e sua relação com a saúde integral da mulher são um aspecto merecedor de atenção. As mulheres vítimas de violência estão mais vulneráveis a dores crônicas, doença mental [estresse, depressão, angústia, etc.], DSTs, gravidez indesejada, aborto [espontâneos e/ou provocados], doença inflamatória pélvica, consumo de drogas, distúrbios gastrointestinais. (FURLANI, 2008, p.27-28)
}

A partir do trecho analisado aqui nos discursos relacionados ao corpo, que mostra uma lembrança da detenta Claudette, juntamente com o trecho transcrito acima, uma discussão sobre a importância do tema violência contra a mulher pode ser iniciada.

Se faz mais do que necessário abordar sexualidade, corpo e gênero nos ambientes escolares. Compreendemos que, apesar da transversalidade indicada ao tema nos documentos oficiais da educação brasileira, no Ensino de Ciências a abertura para tal é um pouco maior, visto que há grande possibilidade de se criarem links com os assuntos estudados. A escola, além da tradicional forma conteudista, deve trazer também os assuntos transversais, pois é também um ambiente de ensino dos valores humanos, como o respeito. Há muito preconceito 
ainda em nosso cotidiano, o que leva aos discursos de ódio, muitas vezes infundados. Precisamos inverter o quadro. O simples fato de trazer dados sobre quantas pessoas são agredidas (física e verbalmente) e mortas, pela opção sexual ou por seu gênero, por exemplo, já faz com que os alunos reflitam sobre esse problema. Muitas vezes é a falta de informação que leva a esses quadros de violência desnecessária e o ambiente escolar é um potencial meio de se difundir tais conhecimentos e promover discussões.

Uma das confluências mais significativas parece ser a de buscar mesclar as aulas tradicionais aos meios alternativos, como o proposto pelo presente artigo. Nesse sentido, a inserção de mídias e artefatos midiáticos, como a série em questão, fazem com que o aluno tenha maior interesse e se sinta parte real daquilo que está estudando, além de promover uma maior criticidade, pois, discutir os sentidos e discursos possíveis no contato com essas mídias, confere a possibilidade de uma formação mais crítica e de respeito das diferenças, perante os temas sexualidade, corpo e gênero. 


\title{
Media representations of body, gender and sexuality - an analysis of the TV Show Orange Is The New Black
}

\begin{abstract}
The media crosses, defines and completes our daily interactions. At school this has not been any different. However, due to lack of theoretical-practical appropriation and little didactic visibility, some media artifacts, when associated with the pedagogical aspect, can be negatively generalized as villains and cause of indiscipline. Starting from these ideas, as wel as from our experiences in school, together with the assumption of some controversial issues / taboos in current discourses, this article will analyze the excerpts from the American series "Orange Is The New Black", accessed often by school-age youth and adolescents. In order to do so we will use the French Discourse Analysis (DA) for discussing how the themes sexuality, body and gender are represented in the series, besides analyzing how these representations can influence the construction of meanings about such themes. We will also try to verify if there is a possibility of learning from the media in the scope of Science Teaching, in a more contextualized approach to sex education. The series presents social contents, which can be discussed in the classroom for the study of cross-cutting themes, especially in relation to sexual education and in the themes sexuality, body and gender, in an alternative to the biological-hygienist approach, from other aspects such as human and sexual rights.
\end{abstract}

KEYWORDS: Media. Sexuality, Body and Gender. Sex Education. Discourse analysis. 


\section{NOTAS}

${ }^{1}$ Informação disponível em https://goo.gl/Yr28rc.

${ }^{2}$ Gays, Lésbicas, Travestis, Transexuais e Transgêneros.

\section{REFERÊNCIAS}

BARBOSA, B. R. S. N.; DA SILVA, L. V.. Morte e exclusão: crimes contra a mulher transexual. Revista Gênero \& Direito, v. 4, n. 1, 2015.

BÉVORT, E.; BELLONI, M. L. Mídia-educação: conceitos, histórias e perspectivas. Educ. Soc., Campinas, vol. 30, n. 109, p. 1081-1102, set./dez. 2009

CHARAUDEAU, P.; MAINGUENEAU, D. Dicionário de Análise do Discurso. 2ª ed. São Paulo: Contexto, 2008.

DAS DEZ SÉRIES MAIS VISTAS NA NETFLIX, SÓ DUAS SÃO DA NETFLIX. UOL. Disponível em: <http://noticiasdatv.uol.com.br/noticia/series/das-dez-seriesmais-vistas-na-netflix-so-duas-sao-da-netflix--15507>. Acesso em: 11 set. 2017.

FAÚNDES, A.; ROSAS, C. F.; BEDONE, A. J.; OROZCO, L. T. Violência sexual: procedimentos indicados e seus resultados no atendimento de urgência de mulheres vítimas de estupro. Rev Bras Ginecol Obstet, v. 28, n. 2, p. 126-35, 2006.

FREIRE, L.; CARDINALI, D. O ódio atrás das grades: da construção social da discriminação por orientação sexual à criminalização da homofobia. Sexualidad, Salud y Sociedad-Revista Latinoamericana, n. 12, 2012.

FURLANI, . (Org.) Educação Sexual na Escola: Equidade de gênero, livre orientação sexual e igualdade étnico-racial numa proposta de respeito as diferenças. Florianópolis, SC: UDESC, 2008.

GAMBARDELLA, A. M. D.; BISMARCK-NASI, E. M. Televisão e predisposição à obesidade em adolescentes. Rev. paul. pediatr, v. 18, n. 1, p. 18-21, 2000.

LEITE, M. M. R. Expressividades e resistências: o corpo em decreto de morte na performance dízimo. Revista Periódicus, v. 1, n. 4, p. 107-119, 2016. subjetivas de controle heteronormativo?. Athenea Digital. Revista de pensamiento e investigación social, n. 17, 2010. 
NETFLIX. Orange Is The New Black. Disponível em:

<https://www.netflix.com/br/>. Acesso em: 14 set. 2017.

ORLANDI, E. P. Análise do discurso: princípios e procedimentos. 5ạ edição.

Campinas: Pontes, 2003.

ORLANDI, E. P. As formas do silêncio. 6 ed. Campinas: Editora Unicamp. 2007. $184 p$.

POSSENTI, S. A linguagem politicamente correta e a análise do discurso. Revista de estudos da linguagem, v. 3, n. 2, p. 123-140, 1995.

RAMOS, M. B. Discursos sobre ciência \& tecnologia no Jornal Nacional. 2006. Disponível em <https://goo.gl/R6JuBw> [Consultado em 16/06/2017]

REEVES, T. C. Do Generational Differences Matter in Instructional Design? ITForum Janeiro. 2008. [Em Linha] Disponível em: <https://goo.gl/Q4HF1C> [Consultado em 16/06/2017]

ROSELLI-CRUZ, A. Homossexualidade, homofobia e a agressividade do palavrão. Seu uso na educação sexual escolar. Educar em Revista, n. 39, p. 73-85, 2011.

SELLES, S.; FERREIRA, M. S. Formação docente em Ciências: memórias e práticas. Niterói: EdUFF, 2003.

Recebido: 31 jan. 2018

Aprovado: 24 jun. 2018

DOI: $10.3895 /$ actio.v3n3.7710

Como citar:

SCHLÖSSER, T. C.; PEREIRA, P. B. Representações midiáticas de corpo, gênero e sexualidade - uma análise da série Orange Is The New Black. ACTIO, Curitiba, v. 3, n. 3, p. 271-291, set./dez. 2018. Disponível em: <https://periodicos.utfpr.edu.br/actio>. Acesso em: XXX

Correspondência:

Tainá Cordova Schlösser

Rua Fernando de Noronha, n. 637, Bairro Santa Cândida, Curitiba, Paraná, Brasil.

Direito autoral: Este artigo está licenciado sob os termos da Licença Creative Commons-Atribuição 4.0

Internacional. 